\title{
Small molecules block the polymerisation of $Z \alpha_{1}$-antitrypsin and increase the clearance of intracellular aggregates
}

\author{
Meera Mallya ${ }^{1,{ }^{*}, \text { Russell L. Phillips }}{ }^{1,{ }^{*}, \text { S. Adrian Saldanha }}{ }^{2,{ }^{*}, \text { Bibek Gooptu}}{ }^{1}$, Sarah C. Leigh \\ Brown ${ }^{1}$, Daniel J. Termine ${ }^{3}$, Arash M. Shirvani ${ }^{3}$, Ying $\mathbf{W u}^{3}$, Richard N. Sifers ${ }^{3}$, Ruben \\ Abagyan $^{2,} \Psi$, and David A Lomas $1, \Psi$ \\ 1 Department of Medicine, University of Cambridge, Cambridge Institute for Medical Research, Wellcome \\ Trust/MRC building, Cambridge CB2 2XY, UK \\ 2 Department of Molecular Biology, The Scripps Research Institute, La Jolla, California 92037, USA \\ 3 Departments of Pathology, Molecular \& Cellular Biology, and Molecular Physiology \& Biophysics, Baylor \\ College of Medicine, One Baylor Plaza, Houston, Texas 77030, USA
}

\begin{abstract}
The Z mutant of $\alpha_{1}$-antitrypsin (Glu342Lys) causes a domain-swap and the formation of intrahepatic polymers that aggregate as inclusions and predispose the homozygote to cirrhosis. We have identified an allosteric cavity that is distinct from the interface involved in polymerisation for rational structurebased drug design to block polymer formation. Virtual ligand screening was performed on 1.2 million small molecules and 6 compounds were identified that reduced polymer formation in vitro. Modelling the effects of ligand binding on the cavity and re-screening the library identified an additional 10 compounds that completely blocked polymerisation. The best antagonists were effective at ratios of compound to $\mathrm{Z} \alpha_{1}$-antitrypsin of 2.5:1 and reduced the intracellular accumulation of $\mathrm{Z} \alpha_{1}$-antitrypsin by $70 \%$ in a cell model of disease. Identifying small molecules provides a novel therapy for the treatment of liver disease associated with the $\mathrm{Z}$ allele of $\alpha_{1}$-antitrypsin.
\end{abstract}

\section{Keywords}

hepatic inclusions; cirrhosis; serpinopathies; drug design; serpins

\section{Introduction}

$\alpha_{1}$-Antitrypsin is synthesised in the liver and released into the plasma where it is the most abundant circulating protease inhibitor. Most individuals carry the normal $\mathrm{M}$ allele of $\alpha_{1}$ antitrypsin but $4 \%$ of the Northern European population are heterozygous for the severe $\mathrm{Z}$ deficiency variant (Glu342Lys). The $\mathrm{Z}$ mutation perturbs the relationship between $\beta$-sheet $\mathrm{A}$ and the exposed mobile reactive loop that binds to the target proteinase (Fig. 1) ${ }^{1}$. The resulting unstable intermediates $^{2-4}$ then link sequentially to form loop-sheet polymers in which the reactive centre loop of one $\alpha_{1}$-antitrypsin molecule inserts as strand 4 of $\beta$-sheet $\mathrm{A}$ of another $2,3,5-7$. It is this accumulation of polymers within the endoplasmic reticulum of

Authors for correspondence: Professor David Lomas, Department of Medicine, University of Cambridge, Cambridge Institute for Medical Research, Wellcome Trust/MRC building, Hills Road, Cambridge, CB2 2XY, U.K. Tel: +44 (0)1223 762818 Fax: +44 (0)1223 336827. Email: dal16@cam.ac.uk and Prof. Ruben Abagyan Department of Molecular Biology, The Scripps Research Institute, La Jolla,

California 92037, USA. Tel: +1 858 7848595, Fax: +1 8587848299 Email: abagyan@ scripps.edu.

${ }^{*}$ These authors made equal contributions to this work

$\Psi$ These laboratories contributed equally to this work 
hepatocytes that underlies the Periodic acid Schiff positive inclusions that are the hallmark of $\mathrm{Z} \alpha_{1}$-antitrypsin deficiency ${ }^{5,8-10}$. These inclusions predispose the $\mathrm{Z} \alpha_{1}$-antitrypsin homozygote to hepatitis ${ }^{11}$, cirrhosis and hepatocellular carcinoma ${ }^{12}$. The resulting lack of circulating $\alpha_{1}$-antitrypsin allows uncontrolled proteolytic digestion within the lung and early onset panlobular emphysema (see reference ${ }^{13}$ for review).

$\alpha_{1}$-Antitrypsin is the archetypal member of the serine proteinase inhibitor or serpin superfamily. The process of polymer formation is now recognised to underlie diseases associated with other members of this family. For example mutants of antithrombin ${ }^{14,15}, \mathrm{C} 1$ inhibitor $^{16,17}$ and $\alpha_{1}$-antichymotrypsin ${ }^{3,18}$ cause the protein to form polymers that are retained within the liver thereby causing a plasma deficiency that results in thrombosis, angioedema and emphysema respectively. Perhaps most striking is our description of mutants of a neurone-specific protein, neuroserpin, that polymerise to cause a novel inclusion body dementia that we have called familial encephalopathy with neuroserpin inclusion bodies or FENIB ${ }^{19,20}$. In view of the common mechanism that underlies these disorders we have grouped them together as a new class of disease, the 'serpinopathies' 21 .

The only curative treatment currently available for the cirrhosis associated with $\alpha_{1}$-antitrypsin deficiency is liver transplantation. Thus it is essential to develop effective strategies to block polymerisation in order to treat the associated disease ${ }^{22}$. Previous approaches have focused on chemical chaperones ${ }^{23,24}$ that stabilise the mutant protein and reactive loop peptides that can bind as strand 4 of $\beta$-sheet A of $Z \alpha_{1}$-antitrypsin and so prevent the acceptance of an exogeneous reactive loop 4,25 . However neither strategy has yet been proven to be a viable therapeutic option in man ${ }^{26}$. Finding a small drug that can bind to $\alpha_{1}$-antitrypsin and prevent polymerisation in vitro and in vivo is particularly challenging. Ideally, this small molecule should bind to a region of the protein that is distinct from the strand 4 position of $\beta$-sheet $A$ for although this is the binding site of exogenous reactive loop peptides to form polymers (Fig. 1a), it is also critical for the inhibitory function of $\alpha_{1}$-antitrypsin 27 .

A lateral hydrophobic pocket was identified in crystal structures of $\alpha_{1}$-antitrypsin 1,28 . This pocket is lined by strand 2 of $\beta$-sheet $A$ and $\beta$-helices $D$ and $E$ (Fig. 1a). It is patent in the native protein but is occupied as $\beta$-sheet $\mathrm{A}$ accepts an exogenous reactive loop peptide during polymer formation ${ }^{1}$. The potential utility of the cavity as a target for rational drug design was demonstrated by the introduction of the 'cavity-filling' mutation Thr114Phe ${ }^{29}$. This mutation retarded polymer formation and increased the secretion of $\mathrm{Z} \alpha_{1}$-antitrypsin from a Xenopus oocyte expression system ${ }^{29}$. However it is unknown whether this pocket could be targeted with sufficient affinity by a small molecule ligand. We report here the use of structure based drug discovery to identify a lead small molecule antagonist that can bind to the lateral hydrophobic pocket of $\mathrm{Z} \alpha_{1}$-antitrypsin and block polymerisation in vitro and in a cell model of disease.

\section{Results and Discussion}

\section{In silico screening to identify small molecules that antagonise the polymerisation of $\alpha_{1^{-}}$ antitrypsin}

The ICM PocketFinder analysis tool ${ }^{30}$ was used to determine if either of the two high resolution structures of native $\alpha_{1}$-antitrypsin (PDB codes: $1 \mathrm{QLP}^{1}$ and $1 \mathrm{HP}^{28}$ ) would be suitable for virtual screening. The lateral hydrophobic cavity was identified as being 'druggable' in both structures but the cavity in structure 1QLP was better suited to binding small molecules. Virtual screening with the ICM software suite (Molsoft L.L.C.) against a non-redundant library of approximately 1.2 million commercial drug-like compounds was performed on the original crystallographic coordinates (PDB 1QLP) of the lateral hydrophobic pocket. However, compounds nominated from screening the deposited structure were not effective in preventing 
the polymerisation of $Z \alpha_{1}$-antitrypsin. As a consequence side chain simulation analysis (see 'Experimental section') was performed in order to identify the most flexible residues that line the cavity. Asn104 was highlighted by computational analysis as the most flexible residue. Visual inspection confirmed that this residue had the most significant effects on the dimensions and drugability of the cavity. An alternate conformation for this target site was generated by modelling low energy conformations for Asn104 through internal coordinate Monte Carlo side chain simulations ${ }^{31}$. The resulting conformation differs from the PDB structure only in the position of the Asn 104 side chain by $0.5 \AA$ root-mean-square deviation (RMSD) after optimal superposition.

Virtual screening with the non-redundant library of 1.2 million commercial drug-like compounds was then performed with this alternate conformation of $\alpha_{1}$-antitrypsin. Sixty-eight compounds from the initial screen of 1.2 million small molecules were selected for further characterisation in vitro.

\section{Assessment of the effect of small molecules on polymerisation, structure and function of $\alpha_{1}$-antitrypsin}

Most compounds nominated from the screen had no or negligible effects on polymerisation (Fig. 2) while some even accelerated polymer formation. Four compounds (denoted Jub, AG, $\mathrm{CO}$ and DV; Fig. 1c) reduced the rate of polymerisation, one compound (PC; Fig. 1c) prevented the formation of higher molecular mass polymers and one compound (CG; Fig. 1d) completely blocked polymerisation (Figs. 2a and 2b). CG (see Fig. $1 \mathrm{~b}$ for predicted binding pose) completely blocked the polymerisation of $\mathrm{Z} \alpha_{1}$-antitrypsin at $50 \mu \mathrm{M}$ ( 25 -fold molar excess) but was still effective at reducing polymerisation at $20 \mu \mathrm{M}$ (10-fold molar excess) (Fig. 2c). PC effectively reduced polymerisation at $10 \mu \mathrm{M}$ (5-fold molar excess) although a dimer band was still present (Fig. 2d). CG and PC, and indeed all the compounds that reduced polymerisation of $\mathrm{Z} \alpha_{1}$-antitrypsin caused an anodal band shift in the residual monomeric protein when analysed by non-denaturing polyacrylamide gel electrophoresis (PAGE). Further analysis demonstrated that $C G$ induced the band shift of $Z \alpha_{1}$-antitrypsin between 8 and 18 hours when incubated in 100-fold molar excess (data not shown). The band shift was not due to cleavage of the protein (as assessed by N-terminal sequencing analysis), denaturation (as assessed by far UV circular dichroism) or covalent linkage as CG is chemically inert. However the $\mathrm{Z} \alpha_{1}$ antitrypsin:CG complex was remarkably stable with a melting temperature in excess of $100^{\circ}$ $\mathrm{C}$ (which compares to a $\mathrm{T}_{\mathrm{m}}$ of $54.1^{\circ} \mathrm{C}$ in $3.7 \% \mathrm{v} / \mathrm{v}$ ethanol in the absence of $\mathrm{CG}$ ) and was inactive as a proteinase inhibitor. It was not possible to determine a value for the $\mathrm{K}_{\mathrm{d}}$ between $\mathrm{CG}$ and $\mathrm{Z} \alpha_{1}$-antitrypsin using intrinsic tryptophan fluorescence. We therefore used dialysis to determine whether this interaction with the compound led to an irreversible transition. Z $\alpha_{1}$-antitrypsin was incubated with a 100 -fold molar excess of $\mathrm{CG}$ at $37^{\circ} \mathrm{C}$ for 3 days and then extensively dialysed ( $3 \times 1$ litre) against PBS. The anodal band shift remained after dialysis (Fig. 3a) with the complex being resistant to polymerisation when heated at $0.1 \mathrm{mg} / \mathrm{ml}$ for a further 3 hours at $60^{\circ} \mathrm{C}$. Thus the interaction between $\mathrm{CG}$ and $\mathrm{Z} \alpha_{1}$-antitrypsin, or the conformational transition that ensues, was resistant to dialysis leading to a permanent nonpolymerisable state.

Mass spectrometry was used to assess the binding of $C G$ to $Z \alpha_{1}$-antitrypsin. Identical digest products were obtained for both $\mathrm{Z} \alpha_{1}$-antitrypsin and the $\mathrm{Z} \alpha_{1}$-antitrypsin:CG complex. There was $70 \%$ coverage of the protein sequence but $C G$ was not associated with any of the identified fragments. 


\section{Assessment of the effect of small molecules on polymerisation of other member of the serpin superfamily}

Members of the serine proteinase inhibitor or serpin superfamily are structurally homologous, but the lateral hydrophobic pocket is not present in antithrombin or $\alpha_{1}$-antichymotrypsin ${ }^{1}$. There is currently no crystal structure of native neuroserpin. CG caused an anodal migration of $\alpha_{1}$-antichymotrypsin, antithrombin and wildtype and mutant Syracuse (Ser49Pro) ${ }^{32}$ neuroserpin but did not prevent their polymerisation (Fig. $3 \mathrm{~b}$ and data not shown).

\section{In silico screening following modelling of ligand induced changes in the conformation of $Z$ $\alpha_{1}$-antitrypsin}

Even small ligand induced changes in the conformation of $\mathrm{Z} \alpha_{1}$-antitrypsin can have major effects on binding affinity. These ligand induced changes were modelled for the best compounds, $\mathrm{CG}$ and $\mathrm{PC}$, in order to target more relevant induced-fit pocket conformations for the second round of virtual screening. This was achieved by performing internal coordinate Monte Carlo side chain simulations in the presence of the ligand in its predicted binding pose $^{31}$. The major difference between the resulting two conformations, selected for follow-up virtual screening, and the PDB structure are in the position of Asn104 and His139. Comparison of these conformations to the PDB structure show an RMSD of 0.77 and $1.0 \AA$, respectively.

Virtual screening with the non-redundant library of 1.2 million commercial drug-like compounds against these newly derived conformations identified a further 19 compounds for in vitro testing. Ten of these compounds were structurally similar to the original active compounds, CG or PC. The PC analogue WA (Fig. 1c) had a similar effect to PC by allowing only the formation of dimers. BE and SE reduced polymer formation to the same extent as the parent molecule DV but the analogues of CO (e.g. SI) had little effect (Fig. 1c). The most potent blockers of polymerisation were analogues of CG: LA, ENO, MS, SD, TR, WH and LTM (Figs. $1 \mathrm{~d}$ and 3c). LA completely blocked the polymerisation of $Z \alpha_{1}$-antitrypsin at $50 \mu \mathrm{M}$ (25fold excess) and reduced polymerisation at $10 \mu \mathrm{M}$ (5-fold excess). WA, ENO, MS, SD, TR, WH and LTM completely blocked polymerisation at $10 \mu \mathrm{M}$ (5-fold excess) whilst WA and

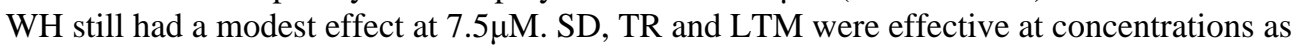
low as $5 \mu \mathrm{M}$ (2.5-fold excess) (Fig. $3 \mathrm{~d}$ and data not shown). Like the parent compounds, all analogues that blocked polymerisation caused an anodal band shift on non-denaturing PAGE and inactivated $\mathrm{Z} \alpha_{1}$-antitrypsin as a proteinase inhibitor. The specificity of the compounds to the lateral hydrophobic pocket was assessed by selecting close analogues predicted not to bind the lateral hydrophobic pocket. None of these compounds (TT, NY and JS; Fig. 1c and 1d) had any demonstrable effect on the polymerisation of $Z \alpha_{1}$-antitrypsin.

\section{Characterisation of the effect of the compounds in a cell model of $Z \alpha_{1}$-antitrypsin deficiency}

The effect of the small molecules on the intracellular fate of $Z \alpha_{1}$-antitrypsin was then assessed in murine hepatoma cells, Hepa1a. CG reduced the intracellular retention of $Z \alpha_{1}$-antitrypsin by $70 \%$ (Fig. 4) in keeping with an accelerated rate of clearance when compared to control cells. The majority of $Z \alpha_{1}$-antitrypsin was cleared 1-3 hours after pulse-labeling compared to 5 hours for $Z \alpha_{1}$-antitrypsin that was not treated with CG. There was no change in the electrophoretic mobility of $Z \alpha_{1}$-antitrypsin when isolated from cells incubated with CG. No increase in the secretion of $Z \alpha_{1}$-antitrypsin was detected (data not shown). Neither NY nor LTM accelerated the degradation nor increased secretion of $Z \alpha_{1}$-antitrypsin in this cell model of disease.

Polymers of $\mathrm{Z} \alpha_{1}$-antitrypsin are retained within hepatocytes where they aggregate to form the inclusions that underlie the associated liver disease. The pathways by which polymers are handled within hepatocytes are now being elucidated. Trimming of asparagine linked oligosaccharides target $\mathrm{Z} \alpha_{1}$-antitrypsin polymers into an efficient non-proteosomal disposal 
pathway within hepatocytes ${ }^{33-35}$. However, the proteosome has an important role in metabolising $Z \alpha_{1}$-antitrypsin in some hepatic 36 and extra-hepatic 37,38 mammalian cell lines. Moreover, there is increasing evidence that the retained $\mathrm{Z} \alpha_{1}$-antitrypsin stimulates an autophagic response within the hepatocyte ${ }^{39-41}$. Our data demonstrate that at least one of the small molecules (CG) is able to increase the clearance of $Z \alpha_{1}$-antitrypsin in a cell model of disease. Further studies are required to define the disposal pathways that clear the $\mathrm{Z} \alpha_{1^{-}}$ antitrypsin:CG complex. However the resulting $\mathrm{Z} \alpha_{1}$-antitrypsin had a normal electrophoretic mobility when isolated from cells which implies that treatment with CG either ablated the trimming of asparagine-linked oligosaccharides or that molecules were more rapidly degraded in response to the accelerated rate at which oligosaccharides were modified, such that only the unmodified population remained. The latter conclusion is most likely correct as cleavage of the appendages is an obligatory step in the intracellular degradation process. In either case the accelerated clearance of mutant protein provides strong support for the likely success of these compounds (or their derivatives) in vivo. The ability of CG to target the mutant protein for degradation would reduce the protein overload and therefore attenuate the hepatic toxicity associated with the accumulation of polymers of $Z \alpha_{1}$-antitrypsin.

\section{In-vitro selectivity of CG}

The Molecular Libraries Screening Center Network (MLSCN) is a consortium of academic laboratories responsible for screening compound libraries against cell and cell-free in-vitro assays (http://grants1.nih.gov/grants/guide/rfa-files/RFA-RM-04-017.html.). As of June 2007, the compound CG (PubChem ID: MLS000521559) has tested negative (between 5 to $10 \mu \mathrm{M}$ ) in all 30 MLSCN screens, including 9 cell (PubChem Assay ID (AID): 598, 602, 620, 648, 710, 719, 729, 731, 736) and 21 cell-free (AID: 583, 568, 618, 619, 629, 631, 632, 633, 639, $640,687,693,690,696,697,701,704,702,717,720,722$ ) assays. The targets in these assays include traditional enzyme active sites (e.g. protein kinase, tyrosine phosphatase and matrix metallo-proteinase), protein-protein and protein-RNA binding sites, as well as cytotoxic and reporter-based cell screens. This wide panel of screens shows that CG is not a promiscuous compound and is therefore less likely to have unwanted off-target effects.

\section{Conclusion}

Taken together our data demonstrate the successful use of structure-based drug design to target a cavity that is distinct from the interface involved in polymerisation of mutant $\alpha_{1}$-antitrypsin. The discovered compounds are effective at reducing the polymerisation of mutant $Z \alpha_{1^{-}}$ antitrypsin in vitro while the lead compound CG reduces aggregates of $Z \alpha_{1}$-antitrypsin in a cell model of disease. CG is highly selective as it is inactive in a diverse range of 29 cell-based and cell-free in-vitro assays. Our strategy represents a novel and highly effective approach to the treatment of the liver disease associated with homozygosity of the $\mathrm{Z}$ allele of $\alpha_{1}$-antitrypsin.

\section{Experimental section}

\section{In silico screening to identify small molecules that antagonise the polymerisation of $\alpha_{1}$ - antitrypsin}

Virtual screening was performed with the original crystallographic coordinates of the lateral hydrophobic pocket of $1 \mathrm{QLP}^{1}$ against a non-redundant library of approximately 1.2 million commercial drug-like compounds from 10 vendors: Asinex (Russia), BioNet (UK), Chembridge (USA), Chemical Diversity (USA), IBS (Russia), Maybridge (USA), SigmaAldrich (USA), Specs (Netherlands), Tripos (USA) and TimTec (Russia). The screen was repeated following an assessment of the flexibility of the side chains of the pocket and modelling the effect of ligand induced changes. In each case the virtual screening results were ranked by their ICM-score and the following conditions were imposed to nominate compounds for biological testing: (i) a permissive cut off score that resulted in only the top $1 \%$ 
(approximately 400) of top scoring compounds being retained, (ii) the location of the ligand in the pocket and (iii) the ligand should make at least one hydrogen bond with the protein.

\section{Side chain flexibility anaylsis}

Analysis of the local flexibility around the lateral hydrophobic pocket was based on an ICM biased probability Monte Carlo simulation ${ }^{31}$ of the 17 side chains surrounding the pocket (N104, L110, Q105, H139, Q109, Q111, S140, L103, S56, L112, N116, L100, T114, T59, N186, I188 and Y138). Only the lowest energy representatives were selected for conformations closer than 15 degrees in side-chain torsion RMSD ${ }^{42}$. The RMSD of atoms with Boltzmannweighted contributions from these filtered low energy conformations were then calculated. The side chain of Asn104 exhibited the maximal possible deviation (3.6̊̊).

\section{Assessment of the effect of small molecules on polymerisation, structure and function of $\alpha_{1}$-antitrypsin}

The lead compounds or analogues were solubilised to $2 \mathrm{mg} / \mathrm{ml}$ in dimethylsulfoxide (DMSO) or $1 \mathrm{mg} / \mathrm{ml}$ in $50 \%(\mathrm{v} / \mathrm{v})$ ethanol before being diluted to $0.4 \mathrm{mg} / \mathrm{ml}$ with PBS. $\alpha_{1}$-Antitrypsin was purified from the plasma of either PiM or PiZ homozygotes 43 and the effect of compounds on polymerisation was assessed by incubation in 100-fold molar excess with $2 \mu \mathrm{g}$ of $\mathrm{Z}$ or M

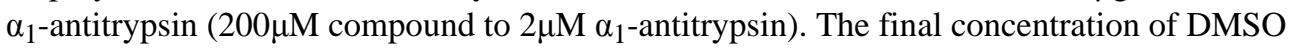
or ethanol was the same for each sample and the controls $(4.75 \%(\mathrm{v} / \mathrm{v})$ and $3.7 \%(\mathrm{v} / \mathrm{v})$ respectively). Circular dichroism (CD) spectroscopy and thermal unfolding experiments were performed as detailed previously ${ }^{29}$. The effect of the compounds on the activity of $\alpha_{1}$ antitrypsin was assessed using an ELISA assay.

\section{Mass spectrometry}

The molecular mass of native $\mathrm{Z} \alpha_{1}$-antitrypsin or $\mathrm{Z} \alpha_{1}$-antitrypsin incubated with the small molecule was determined by MALDI. Assessment of binding of the small molecule to a domain of $\alpha_{1}$-antitrypsin was undertaken by precipitating native $\mathrm{Z} \alpha_{1}$-antitrypsin or $\mathrm{Z} \alpha_{1}$-antitrypsin incubated with the small molecule with acetone and then treating with cyanogen bromide and digesting with trypsin in 4M urea. This was performed with or without treatment with PNGase F to remove the glycans.

\section{Effect of the compounds on other members of the serpin superfamily}

Plasma antithrombin was from Dan Johnson, Dept. of Haematology, University of Cambridge, plasma $\alpha_{1}$-antichymotrypsin was from Sigma and wildtype neuroserpin and the Syracuse mutant of neuroserpin that causes FENIB (Ser49Pro) were purified as described previously ${ }^{32}$. These serpins were incubated at $0.1 \mathrm{mg} / \mathrm{ml}$ in $\mathrm{PBS}$ at $37^{\circ} \mathrm{C}$ or $45^{\circ} \mathrm{C}$ for 3 or 7 days in the presence or absence of $200 \mu \mathrm{M}$ compound and $3.7 \%(\mathrm{v} / \mathrm{v})$ ethanol. The effect on polymerisation was then assessed by $7.5 \%(\mathrm{w} / \mathrm{v})$ non-denaturing PAGE.

\section{Characterisation of the effect of the compounds in a cell model of $Z \alpha_{1}$-antitrypsin deficiency}

The murine hepatoma cell line, Hepala was grown as monolayers in standard growth medium and split into $100-\mathrm{mm}$ dishes at a density of $70 \%$ confluence. The following day cells were transfected with hATZ/pcDNA3.1 Zeo(+) ( $\mathrm{Z} \alpha_{1}$-antitrypsin subcloned into the unique EcoRI site of pcDNA3.1 Zeo (+)) using the Lipofectamine 2000 protocol. Twenty-four hours posttransfection the cells were collected and split at the same density into 60-mm dishes. The small molecules (CG, NY and LTM) were administered forty-eight hours post-transfection at a concentration of $100 \mu \mathrm{M}$ with the scientists being blind to the in vitro efficacy of the compounds that were being assessed. The cells were incubated with the small molecule for 16 hours and then subjected to methionine starvation in methionine-free medium supplemented with the small molecule for thirty minutes. $\left.{ }^{35} \mathrm{~S}\right]$ methionine was added $[0.075 \mathrm{mCi}(1 \mathrm{Ci}=37 \mathrm{GBq})$ per 
60-mm dish] during a twenty minute pulse followed by up to 5-hour chase in serum free DMEM (Gibco/BRL) containing $0.2 \mathrm{mM}$ unlabeled methionine with the small molecule. The cells were lysed with buffered Nonidet P-40 detergent at designed time points and immunoprecipitates were resolved by SDS-PAGE and then detected by fluorography.

\section{Acknowledgements}

This work was supported by the Medical Research Council (UK), the Wellcome Trust, Papworth NHS Trust and the NIH (5R01GM071872 and 1R01GM074832 to RA; 1R01DK064232 and 1R01DK075322 to RNS). MM is the recipient of an Alpha-1 Laurell Training Award (ALTA), RLP is a Wellcome Trust Clinical Research Fellow, BG is a Wellcome Trust Intermediate Fellow and SCLB is a Wellcome Trust Summer Student. We are grateful to Drs Sarah Maslen and Elaine Spencer, Department of Chemistry, University of Cambridge for assistance with mass spectrometry, Dr Charlotte Summers, Department of Medicine, University of Cambridge for the ELISA based activity assay and to Prof. Edwin Chilvers, Department of Medicine, University of Cambridge for helpful advice.

\section{References}

1. Elliott PR, Pei XY, Dafforn TR, Lomas DA. Topography of a $2.0 \AA$ structure of $\alpha_{1}$-antitrypsin reveals targets for rational drug design to prevent conformational disease. Protein Science 2000;9:1274-1281. [PubMed: 10933492]

2. Dafforn TR, Mahadeva R, Elliott PR, Sivasothy P, Lomas DA. A kinetic mechanism for the polymerisation of $\alpha_{1}$-antitrypsin. J Biol Chem 1999;274:9548-9555. [PubMed: 10092640]

3. Gooptu B, Hazes B, Chang W-SW, Dafforn TR, Carrell RW, et al. Inactive conformation of the serpin $\alpha_{1}$-antichymotrypsin indicates two stage insertion of the reactive loop; implications for inhibitory function and conformational disease. Proc Natl Acad Sci (USA) 2000;97:67-72. [PubMed: 10618372]

4. Mahadeva R, Dafforn TR, Carrell RW, Lomas DA. Six-mer peptide selectively anneals to a pathogenic serpin conformation and blocks polymerisation: implications for the prevention of $\mathrm{Z} \alpha_{1}$-antitrypsin related cirrhosis. J Biol Chem 2002;277:6771-6774. [PubMed: 11773044]

5. Lomas DA, Evans DL, Finch JT, Carrell RW. The mechanism of $Z \alpha_{1}$-antitrypsin accumulation in the liver. Nature 1992;357:605-607. [PubMed: 1608473]

6. Sivasothy P, Dafforn TR, Gettins PGW, Lomas DA. Pathogenic $\alpha_{1}$-antitrypsin polymers are formed by reactive loop- $\beta$-sheet A linkage. J Biol Chem 2000;275:33663-33668. [PubMed: 10924508]

7. Purkayastha P, Klemke JW, Lavender S, Oyola R, Cooperman BS, et al. $\alpha_{1}$-antitrypsin polymerisation: A fluorescence correlation spectroscopic study. Biochemistry 2005;44:2642-2649. [PubMed: 15709777]

8. Wu Y, Whitman I, Molmenti E, Moore K, Hippenmeyer P, et al. A lag in intracellular degradation of mutant $\alpha_{1}$-antitrypsin correlates with liver disease phenotype in homozygous PiZZ $\alpha_{1}$-antitrypsin deficiency. Proc Natl Acad Sci USA 1994;91:9014-9018. [PubMed: 8090762]

9. Janciauskiene S, Eriksson S, Callea F, Mallya M, Zhou A, et al. Differential detection of PAS-positive inclusions formed by the Z, Siiyama and Mmalton variants of $\alpha_{1}$-antitrypsin. Hepatology 2004;40:1203-1210. [PubMed: 15486938]

10. An JK, Blomenkamp K, Lindblad D, Teckman JH. Quantitative isolation of alpha-l-antitrypsin mutant $\mathrm{Z}$ protein polymers from human and mouse livers and the effect of heat. Hepatology 2005;41:160167. [PubMed: 15619240]

11. Sveger T. Liver disease in alpha 1 -antitrypsin deficiency detected by screening of 200,000 infants. N Engl J Med 1976;294:1316-1321. [PubMed: 1083485]

12. Eriksson S, Carlson J, Velez R. Risk of cirrhosis and primary liver cancer in alpha 1 -antitrypsin deficiency. N Engl J Med 1986;314:736-739. [PubMed: 3485248]

13. Lomas DA. The selective advantage of $\alpha_{1}$-antitrypsin deficiency. Am J Resp Crit Care Med 2006;173:1072-1077. [PubMed: 16439713]

14. Bruce D, Perry DJ, Borg J-Y, Carrell RW, Wardell MR. Thromboembolic disease due to thermolabile conformational changes of antithrombin Rouen VI (187 AsnØAsp). J Clin Invest 1994;94:22652274. [PubMed: 7989582] 
15. Picard V, Dautzenberg M-D, Villoutreix BO, Orliaguet G, Alhenc-Gelas M, et al. Antithrombin Phe229Leu: a new homozygous variant leading to spontaneous antithrombin polymerisation in vivo associated with severe childhood thrombosis. Blood 2003;102:919-925. [PubMed: 12595305]

16. Aulak KS, Eldering E, Hack CE, Lubbers YPT, Harrison RA, et al. A hinge region mutation in C1inhibitor (Ala $\left.{ }^{436} \emptyset \mathrm{Thr}\right)$ results in nonsubstrate-like behavior and in polymerization of the molecule. J Biol Chem 1993;268:18088-18094. [PubMed: 8349686]

17. Eldering E, Verpy E, Roem D, Meo T, Tosi M. COOH-terminal substitutions in the serpin C1 inhibitor that cause loop overinsertion and subsequent multimerization. J Biol Chem 1995;270:2579-2587. [PubMed: 7852321]

18. Crowther DC, Serpell LC, Dafforn TR, Gooptu B, Lomas DA. Nucleation of $\alpha_{1}$-antichymotrypsin polymerisation. Biochemistry 2002;42:2355-2363. [PubMed: 12600202]

19. Davis RL, Shrimpton AE, Holohan PD, Bradshaw C, Feiglin D, et al. Familial dementia caused by polymerisation of mutant neuroserpin. Nature 1999;401:376-379. [PubMed: 10517635]

20. Davis RL, Shrimpton AE, Carrell RW, Lomas DA, Gerhard L, et al. Association between conformational mutations in neuroserpin and onset and severity of dementia. Lancet 2002;359:22422247. [PubMed: 12103288]

21. Lomas DA, Mahadeva R. Alpha-1-antitrypsin polymerisation and the serpinopathies: pathobiology and prospects for therapy. J Clin Invest 2002;110:1585-1590. [PubMed: 12464660]

22. Sidhar SK, Lomas DA, Carrell RW, Foreman RC. Mutations which impede loop/sheet polymerisation enhance the secretion of human $\alpha_{1}$-antitrypsin deficiency variants. J Biol Chem 1995;270:83938396. [PubMed: 7721731]

23. Burrows JAJ, Willis LK, Perlmutter DH. Chemical chaperones mediate increased secretion of mutant $\alpha_{1}$-antitrypsin $\left(\alpha_{1}\right.$-AT) Z: a potential pharmacologcial strategy for prevention of liver injury and emphysema. Proc Natl Acad Sci USA 2000;97:1796-1801. [PubMed: 10677536]

24. Devlin GL, Parfrey H, Tew DJ, Lomas DA, Bottomley SP. Prevention of polymerization of M and $\mathrm{Z} \alpha_{1}$-antitrypsin $\left(\alpha_{1}\right.$-AT) with Trimethylamine N-Oxide. Implications for the treatment of $\alpha_{1}$-AT deficiency. Am J Respir Cell Mol Biol 2001;24:727-732. [PubMed: 11415938]

25. Chang YP, Mahadeva R, Chang WS, Shukla A, Dafforn TR, et al. Identification of a 4-mer Peptide Inhibitor that Effectively Blocks the Polymerization of Pathogenic $\mathrm{Z} \alpha_{1}$-Antitrypsin. Am J Respir Cell Mol Biol 2006;35:540-548. [PubMed: 16778151]

26. Teckman JH. Lack of effect of oral 4-phenylbutyrate on serum alpha-1-antitrypsin in patients with alpha-1-antitrypsin deficiency: a preliminary study. J Pediatr Gastroenterol Nutr 2004;39:34-37. [PubMed: 15187777]

27. Huntington JA, Read RJ, Carrell RW. Structure of a serpin-protease complex shows inhibition by deformation. Nature 2000;407:923-926. [PubMed: 11057674]

28. Lee C, Maeng J-S, Kocher J-P, Lee B, Yu M-H. Cavities of $\alpha_{1}$-antitrypsin that play structural and functional roles. Prot Sci 2001;10:1446-1453.

29. Parfrey H, Mahadeva R, Ravenhill N, Zhou A, Dafforn TR, et al. Targeting a surface cavity of $\alpha_{1}$ antitrypsin to prevent conformational disease. J Biol Chem 2003;278:33060-33066. [PubMed: 12807889]

30. An J, Totrov M, Abagyan R. Pocketome via comprehensive identification and classification of ligand binding envelopes. Mol Cell Proteomics 2005;4:752-761. [PubMed: 15757999]

31. Abagyan R, Totrov M. Biased probability Monte Carlo conformational searches and electrostatic calculations for peptides and proteins. J Mol Biol 1994;235:983-1002. [PubMed: 8289329]

32. Belorgey D, Crowther DC, Mahadeva R, Lomas DA. Mutant neuroserpin (Ser49Pro) that causes the familial dementia FENIB is a poor proteinase inhibitor and readily forms polymers in vitro. J Biol Chem 2002;277:17367-17373. [PubMed: 11880376]

33. Cabral CM, Choudhury P, Liu Y, Sifers RN. Processing by endoplasmic reticulum mannosidases partitions a secretion-impaired glycoprotein into distinct disposal pathways. J Biol Chem 2000;275:25015-25022. [PubMed: 10827201]

34. Cabral CM, Liu Y, Moremen KW, Sifers RN. Organizational diversity among distinct glycoprotein ER-associated degradation programs. Molec Biol Cell 2002;13:2639-2650. [PubMed: 12181335] 
35. Wu Y, Swulius MT, Moremen KW, Sifers RN. Elucidation of the molecular logic by which misfolded $\alpha 1$-antitrypsin is preferentially selected for degradation. Proc Natl Acad Sci USA 2003;100:82298234. [PubMed: 12815101]

36. Teckman JH, Burrows J, Hidvegi T, Schmidt B, Hale PD, et al. The proteasome participates in degradation of mutant $\alpha_{1}$-antitrypsin $\mathrm{Z}$ in the endoplasmic reticulum of hepatoma-derived hepatocytes. J Biol Chem 2001;276:44865-44872. [PubMed: 11577074]

37. Qu D, Teckman JH, Omura S, Perlmutter DH. Degradation of a mutant secretory protein, $\alpha_{1}$ antitrypsin $\mathrm{Z}$, in the endoplasmic reticulum requires proteosome activity. $\mathrm{J}$ Biol Chem 1996;271:22791-22795. [PubMed: 8798455]

38. Novoradovskaya N, Lee J, Yu Z-X, Ferrans VJ, Brantly M. Inhibition of intracellular degradation increases secretion of a mutant form of $\alpha_{1}$-antitrypsin associated with profound deficiency. J Clin Invest 1998;101:2693-2701. [PubMed: 9637703]

39. Teckman JH, Perlmutter DH. Retention of mutant $\alpha_{1}$-antitrypsin $\mathrm{Z}$ in endoplasmic reticulum is associated with an autophagic response. Am J Physiol Gastrointest Liver Physiol 2000;279:G961G974. [PubMed: 11052993]

40. Perlmutter DH. Liver injury in $\alpha_{1}$-antitrypsin deficiency: an aggregated protein induces mitochondrial injury. J Clin Invest 2002;110:1579-1583. [PubMed: 12464659]

41. Kamimoto T, Shoji S, Hidvegi T, Mizushima N, Umebayashi K, et al. Intracellular inclusions containing mutant alpha1-antitrypsin $\mathrm{Z}$ are propagated in the absence of autophagic activity. $\mathrm{J}$ Biol Chem 2006;281:4467-4476. [PubMed: 16365039]

42. Abagyan R, Argos P. Optimal protocol and trajectory visualization for conformational searches of peptides and proteins. J Mol Biol 1992;225:519-532. [PubMed: 1593634]

43. Lomas DA, Evans DL, Stone SR, Chang W-SW, Carrell RW. Effect of the Z mutation on the physical and inhibitory properties of $\alpha_{1}$-antitrypsin. Biochemistry 1993;32:500-508. [PubMed: 8422359] 


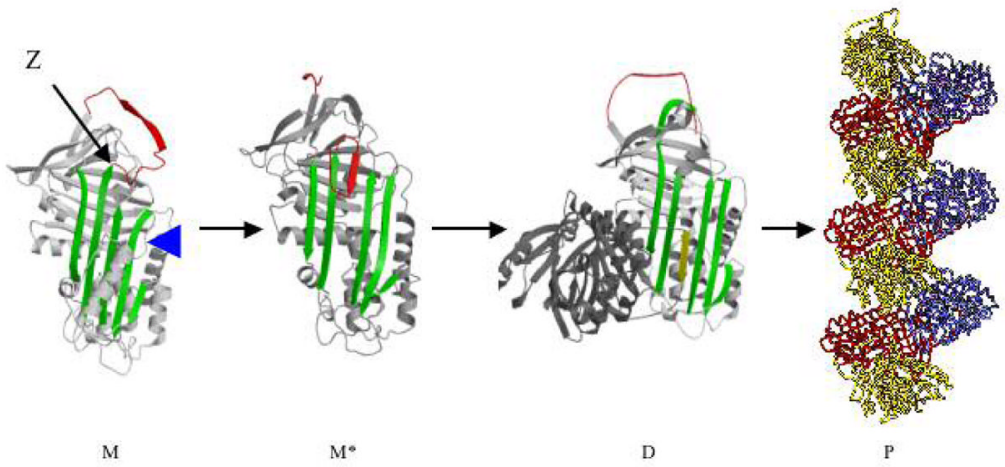

Figure 1a

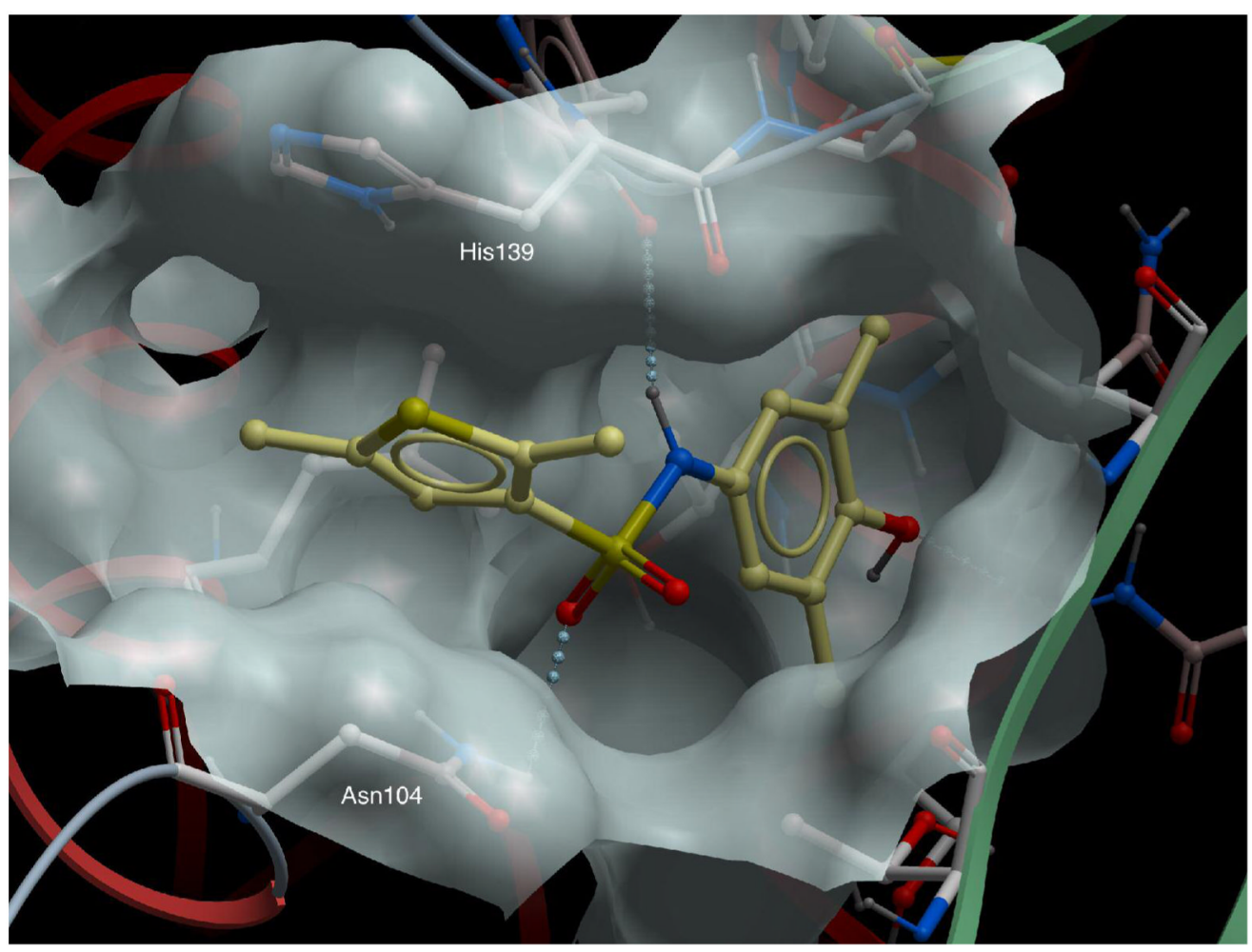

Figure 1b 

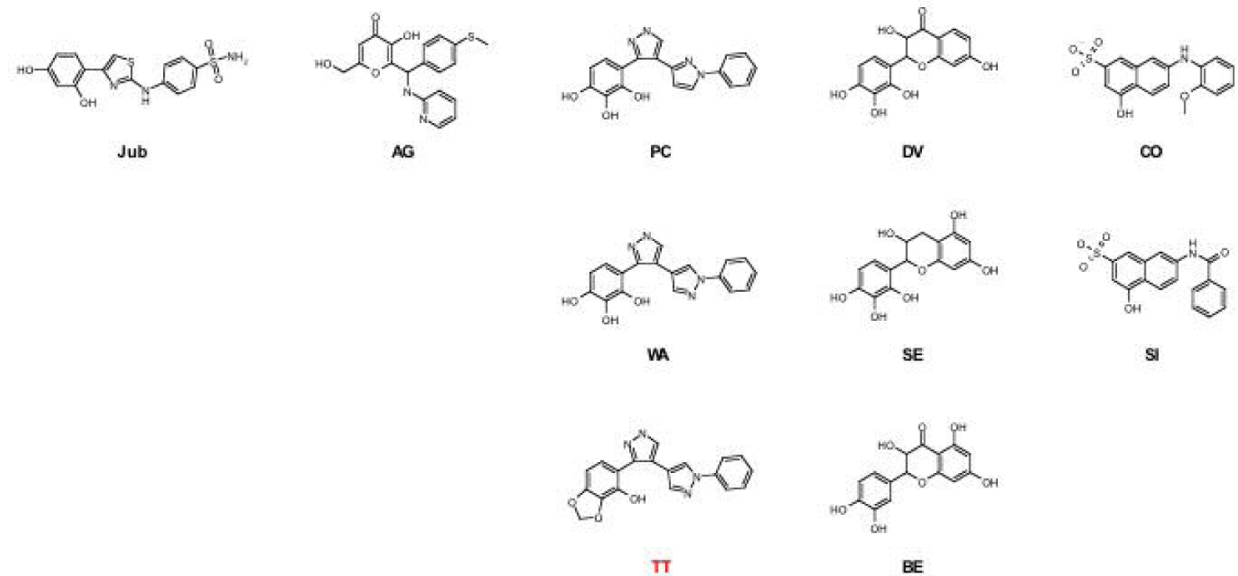

Figure 1c

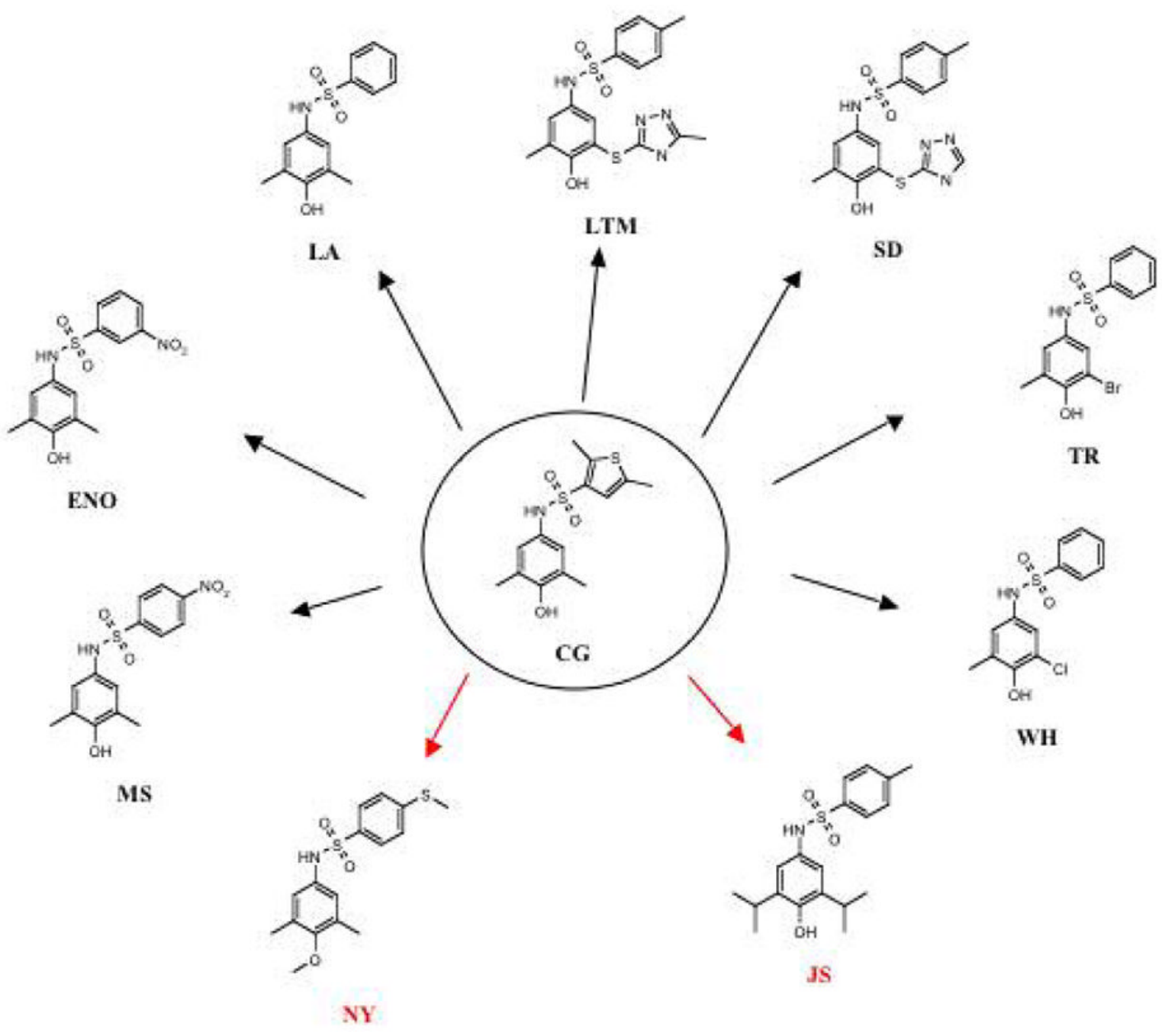

Figure 1d

J Med Chem. Author manuscript; available in PMC 2009 January 27. 
Figure 1.

Rational drug design to prevent the polymerisation of $\alpha_{1}$-antitrypsin. Fig. 1a. Pathway of the polymerisation of $\alpha_{1}$-antitrypsin. The $Z$ mutation of $\alpha_{1}$-antitrypsin (Glu342Lys at $\mathrm{P}_{17}$; arrowed) perturbs the structure of $\beta$-sheet $A$ (green) and the mobile reactive centre loop (red) to form the intermediate $M^{*}$. The patent $\beta$-sheet A can then accept the loop of another molecule (as strand 4 ) to form a dimer (D) which then extends into polymers $(\mathrm{P})^{2-4}$. It is these polymers that accumulate within hepatocytes to cause liver disease 5 . The position of the lateral hydrophobic pocket that is the target of rational drug design is shown with a blue arrowhead. Note the change in conformation in this region of the molecule as it forms $\mathbf{M}^{*}$ and then dimers and polymers. Fig. 1b. The predicted binding pose of CG to the lateral hydrophobic cavity with Asn104 in an alternate conformation. The residues that most effect the dimensions of the pocket, Asn104 and His139, are highlighted. Fig. 1c. The parent compounds Jub, AG, PC, DV and $\mathrm{CO}$ and their analogues that also blocked polymerisation. Compound TT (red) was designed as a control that did not block polymer formation. Fig. 1d. The parent compound CG and its analogues. Compounds labelled in red (NY and JS) are designed not to block polymerisation. 


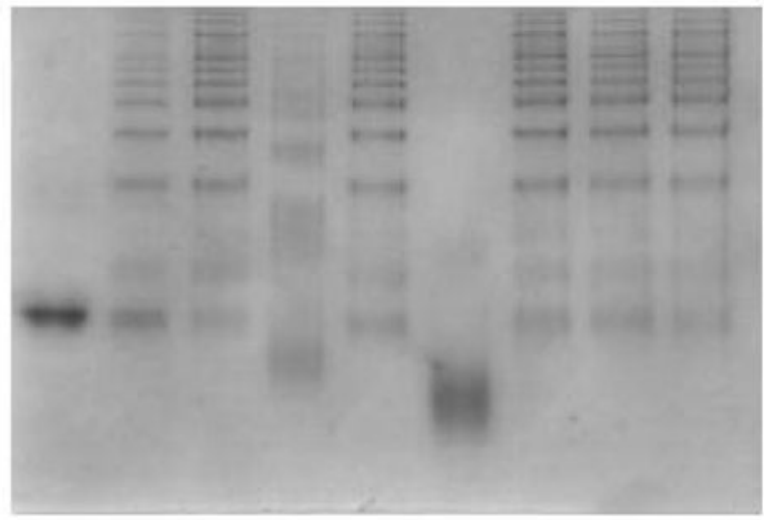

\section{$\begin{array}{lllllllll}1 & 2 & 3 & 4 & 5 & 6 & 7 & 8 & 9\end{array}$}

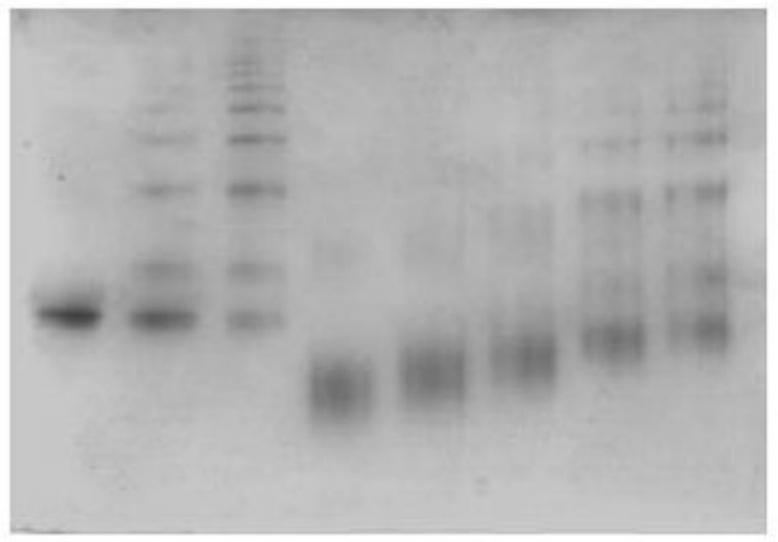

1

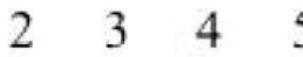

56

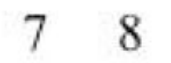

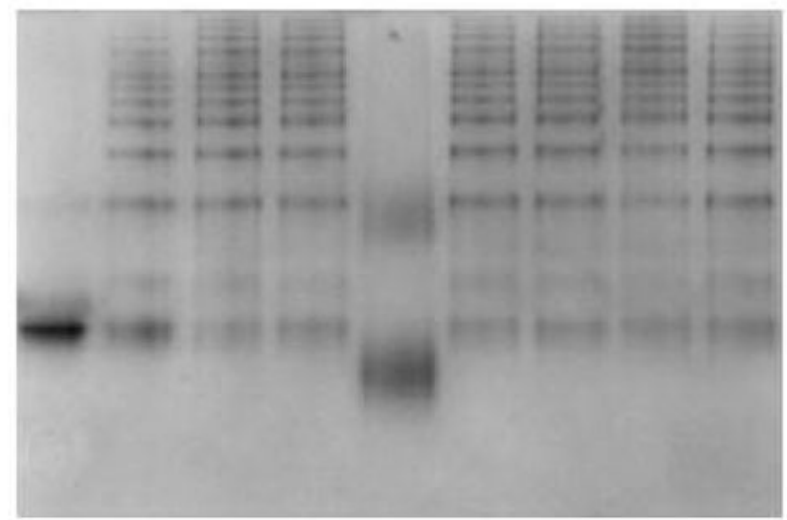
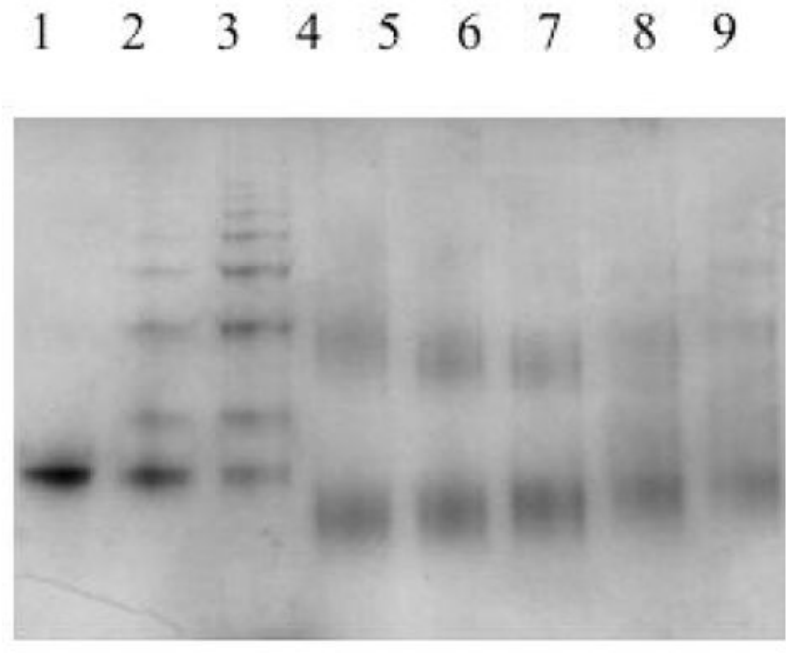

$\begin{array}{lllllll}1 & 2 & 3 & 4 & 5 & 6 & 7\end{array}$

Figure 2.

$7.5 \%(\mathrm{w} / \mathrm{v})$ non-denaturing PAGE to assess the effect of compounds identified in silico on the polymerisation of $\mathrm{Z} \alpha_{1}$-antitrypsin. Each lane contains $2 \mu \mathrm{g}$ of protein. Fig. 2a (top left). Lane 1, monomeric $\mathrm{Z} \alpha_{1}$-antitrypsin; lane $2, \mathrm{Z} \alpha_{1}$-antitrypsin heated at $0.1 \mathrm{mg} / \mathrm{ml}$ and $41^{\circ} \mathrm{C}$ for 7 days; lane $3, \mathrm{Z} \alpha_{1}$-antitrypsin heated at $0.1 \mathrm{mg} / \mathrm{ml}$ and $41^{\circ} \mathrm{C}$ for 7 days in the presence of $4.75 \%$ (v/v) DMSO; lanes 4-9, Z $\alpha_{1}$-antitrypsin heated at $0.1 \mathrm{mg} / \mathrm{ml}$ and $41^{\circ} \mathrm{C}$ for 7 days with 100 fold molar excess of AG, BS, CG, EC, FP and GP respectively, all with a final concentration of $4.75 \%$ (v/v) DMSO. Fig. 2b (top right). Lane 1, monomeric Z $\alpha_{1}$-antitrypsin; lane 2, Z $\alpha_{1^{-}}$ antitrypsin heated at $0.1 \mathrm{mg} / \mathrm{ml}$ and $41^{\circ} \mathrm{C}$ for 7 days; lane $3, \mathrm{Z} \alpha_{1}$-antitrypsin heated at $0.1 \mathrm{mg}$ / $\mathrm{ml}$ and $41^{\circ} \mathrm{C}$ for 7 days in the presence of $4.75 \%$ (v/v) DMSO; lanes 4-9, Z $\alpha_{1}$-antitrypsin heated at $0.1 \mathrm{mg} / \mathrm{ml}$ and $41^{\circ} \mathrm{C}$ for 7 days with 100 -fold molar excess of OC, PC, RS, SK, TCR and UX respectively, all with a final concentration of $4.75 \%(\mathrm{v} / \mathrm{v})$ DMSO. Fig. 2c (bottom left). $7.5 \%(\mathrm{w} / \mathrm{v})$ non-denaturing PAGE to assess the effect of decreasing concentrations of $\mathrm{CG}$ on the polymerisation of $\mathrm{Z} \alpha_{1}$-antitrypsin. Lane 1 , monomeric $\mathrm{Z} \alpha_{1}$-antitrypsin; lane $2, \mathrm{Z}$ $\alpha_{1}$-antitrypsin heated at $0.1 \mathrm{mg} / \mathrm{ml}$ and $41^{\circ} \mathrm{C}$ for 3 days; lane $3, \mathrm{Z} \alpha_{1}$-antitrypsin heated at $0.1 \mathrm{mg}$ / $\mathrm{ml}$ and $41^{\circ} \mathrm{C}$ for 3 days in the presence of $4.75 \%$ (v/v) DMSO; lanes 4-8, Z $\alpha_{1}$-antitrypsin heated at $0.1 \mathrm{mg} / \mathrm{ml}$ and $41^{\circ} \mathrm{C}$ for 3 days with $200 \mu \mathrm{M}, 100 \mu \mathrm{M}, 50 \mu \mathrm{M}, 20 \mu \mathrm{M}$ and $10 \mu \mathrm{M} \mathrm{CG}$ respectively, all with a final concentration of $4.75 \%$ (v/v) DMSO. Fig. 2d (bottom right). 7.5 $\%(\mathrm{w} / \mathrm{v})$ non-denaturing PAGE to assess the effect of decreasing concentrations of PC on the polymerisation of $\mathrm{Z} \alpha_{1}$-antitrypsin. Lane 1 , monomeric $\mathrm{Z} \alpha_{1}$-antitrypsin; lane $2, \mathrm{Z} \alpha_{1}$ - 
antitrypsin heated at $0.1 \mathrm{mg} / \mathrm{ml}$ and $41^{\circ} \mathrm{C}$ for 3 days; lane $3, \mathrm{Z} \alpha_{1}$-antitrypsin heated at $0.1 \mathrm{mg} /$ $\mathrm{ml}$ and $41^{\circ} \mathrm{C}$ for 3 days in the presence of $4.75 \%$ (v/v) DMSO; lanes 4-8, $\mathrm{Z} \alpha_{1}$-antitrypsin heated at $0.1 \mathrm{mg} / \mathrm{ml}$ and $41^{\circ} \mathrm{C}$ for 3 days with $200 \mu \mathrm{M}, 100 \mu \mathrm{M}, 50 \mu \mathrm{M}, 20 \mu \mathrm{M}$ and $10 \mu \mathrm{M}$ PC respectively, all with a final concentration of $4.75 \%(\mathrm{v} / \mathrm{v})$ DMSO. 


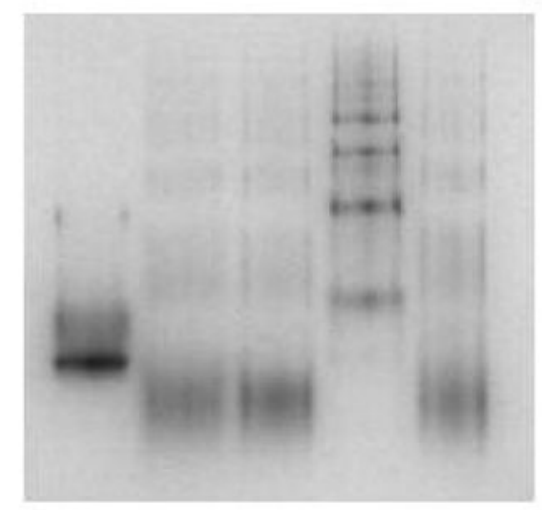

$\begin{array}{lllll}1 & 2 & 3 & 4 & 5\end{array}$

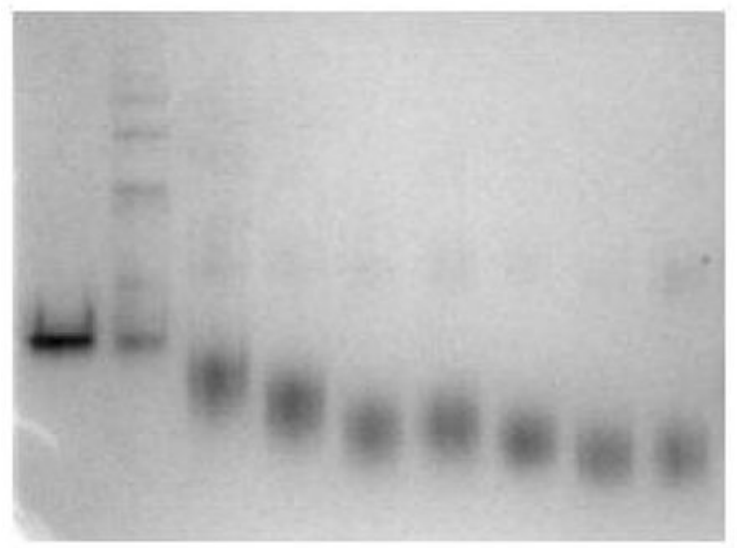

$\begin{array}{lllllllll}1 & 2 & 3 & 4 & 5 & 6 & 7 & 8 & 9\end{array}$

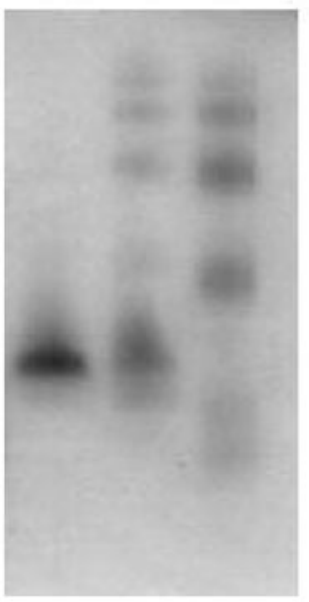

123

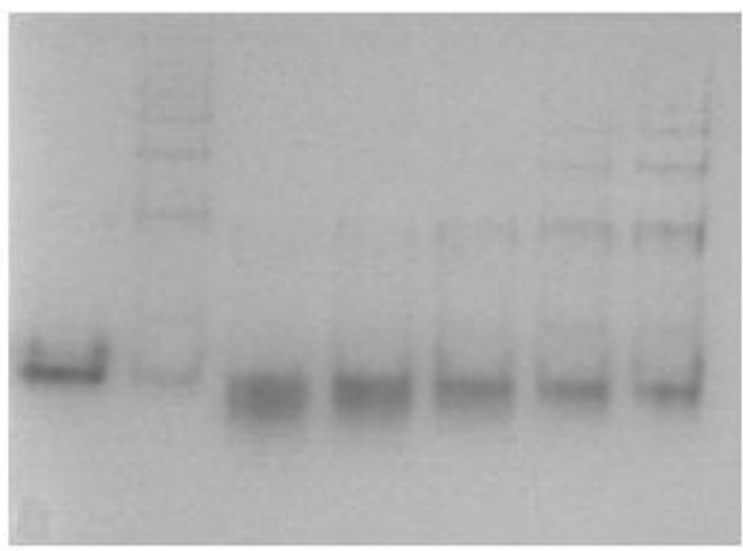

$\begin{array}{llllll}1 & 2 & 3 & 4 & 5 & 6\end{array}$ 7

Figure 3.

The binding of $\mathrm{CG}$ and its analogues to $\mathrm{Z} \alpha_{1}$-antitrypsin and other serpins. Fig. 3a (top left). $7.5 \%(\mathrm{w} / \mathrm{v})$ non-denaturing PAGE with each lane containing $2 \mu \mathrm{g}$ protein. The interaction between $\mathrm{Z} \alpha_{1}$-antitrypsin and CG leads to an irreversible transition. Lane $1, \mathrm{Z} \alpha_{1}$-antitrypsin; lane $2, \mathrm{Z} \alpha_{1}$-antitrypsin incubated with $\mathrm{CG}$ at $37^{\circ} \mathrm{C}$ for 3 days; lane $3, \mathrm{Z} \alpha_{1}$-antitrypsin incubated with $\mathrm{CG}$ at $37^{\circ} \mathrm{C}$ for 3 days and then dialysed in $3 \times 11 \mathrm{PBS}$; lane $4, \mathrm{Z} \alpha_{1}$-antitrypsin heated at $0.1 \mathrm{mg} / \mathrm{ml}$ and $60^{\circ} \mathrm{C}$ for 3 hours; lane $5, \mathrm{Z} \alpha_{1}$-antitrypsin incubated with $\mathrm{CG}$ at $37^{\circ} \mathrm{C}$ for 3 days, dialysed in $3 \times 11$ PBS and then heated at $0.1 \mathrm{mg} / \mathrm{ml}$ and $60^{\circ} \mathrm{C}$ for 3 hours. Fig. $3 \mathrm{~b}$ (top right). $\mathrm{CG}$ does not inhibit the polymerisation of $\alpha_{1}$-antichymotrypsin. $7.5 \%(\mathrm{w} / \mathrm{v})$ non-denaturing PAGE with each lane containing $2 \mu \mathrm{g}$ protein. Lane $1, \alpha_{1}$-antichymotrypsin; lane $2, \alpha_{1}$ antichymotrypsin heated at $0.1 \mathrm{mg} / \mathrm{ml}$ and $45^{\circ} \mathrm{C}$ for 3 days in $3.7 \%(\mathrm{v} / \mathrm{v})$ ethanol; lane $3, \alpha_{1^{-}}$ antichymotrypsin incubated at $0.1 \mathrm{mg} / \mathrm{ml}$ and $45^{\circ} \mathrm{C}$ for 3 days with $\mathrm{CG}$ in $3.7 \%(\mathrm{v} / \mathrm{v})$ ethanol. Fig. 3c (bottom left). Effect of the analogues of $C G$ on the polymerisation of $Z \alpha_{1}$-antitrypsin. Lane $1, \mathrm{Z} \alpha_{1}$-antitrypsin; lane $2, \mathrm{Z} \alpha_{1}$-antitrypsin heated at $0.1 \mathrm{mg} / \mathrm{ml}$ and $37^{\circ} \mathrm{C}$ for 3 days in $3.7 \%$ (v/v) ethanol; lanes 3-9, $\mathrm{Z} \alpha_{1}$-antitrypsin heated at $0.1 \mathrm{mg} / \mathrm{ml}$ and $37^{\circ} \mathrm{C}$ for 3 days in 100 fold molar excess of CG, LA, ENO, MS, SD, TR and WH respectively, all with a final concentration of $3.7 \%$ (v/v) ethanol. Fig. 3d (bottom right). Effect of the LTM on the polymerisation of $\mathrm{Z} \alpha_{1}$-antitrypsin. Lane $1, \mathrm{Z} \alpha_{1}$-antitrypsin; lane $2 \mathrm{Z} \alpha_{1}$-antitrypsin heated at 
$0.1 \mathrm{mg} / \mathrm{ml}$ and $37^{\circ} \mathrm{C}$ for 3 days in $3.7 \%$ (v/v) ethanol; lanes $3-7, \mathrm{Z} \alpha_{1}$-antitrypsin heated at $0.1 \mathrm{mg} / \mathrm{ml}$ and $37^{\circ} \mathrm{C}$ for 3 days in $10 \mu \mathrm{M}, 7.5 \mu \mathrm{M}, 5 \mu \mathrm{M}, 2.5 \mu \mathrm{M}$ and $1 \mu \mathrm{M}$ of LTM respectively, all with a final concentration of $3.7 \%(\mathrm{v} / \mathrm{v})$ ethanol. 


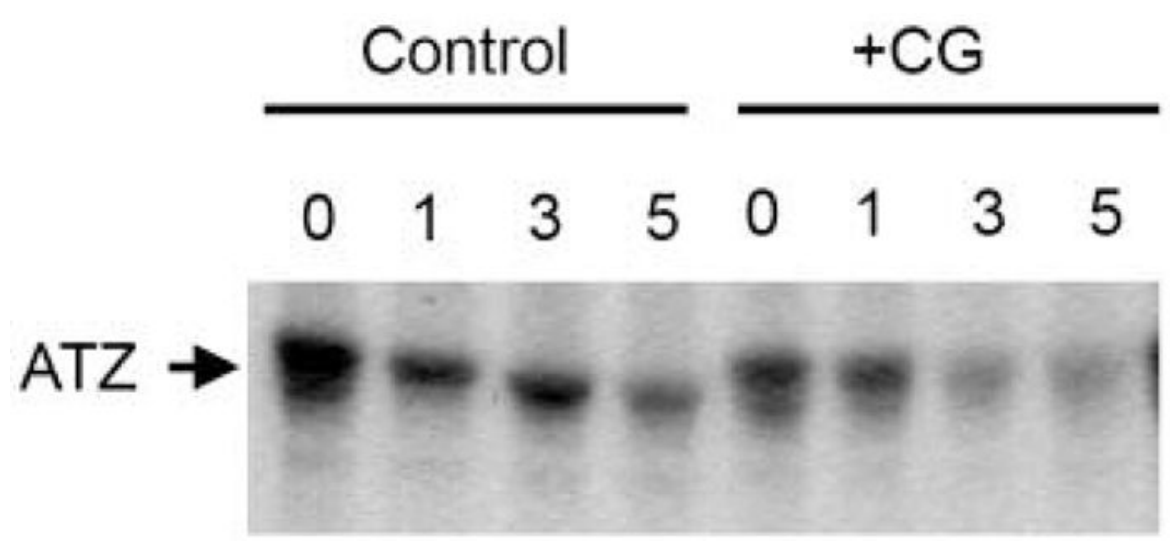

Figure 4.

The effect of CG on the secretion of $Z \alpha_{1}$-antitrypsin. Hepala cells were transiently transfected with $\mathrm{Z} \alpha_{1}$-antitrypsin in the presence or absence of CG. Lanes 1-4, Z $\alpha_{1}$-antitrypsin radiolabeled with $\left[{ }^{35} S\right]$ methionine and chased up to 5 hours. Immunoprecipitation experiments demonstrate that the half-life of the $\mathrm{Z}$ variant is between 3-5 hours. Lanes 5-8, transfected Hepa1a cells were treated with $100 \mu \mathrm{M} \mathrm{CG}$ for $16 \mathrm{~h}$ prior to the pulse-chase experiment. $\mathrm{Z} \alpha_{1}$ antitrypsin was radiolabeled with $\left.{ }^{35} S\right]$ methionine in the presence of $C G$ and chased up to 5 hours. Glycan trimming of $\mathrm{Z} \alpha_{1}$-antitrypsin was not detected in association with an increased rate of intracellular clearance. 